\title{
Bluetooth Controlled Car System
}

\author{
Shrutika Kanere ${ }^{1}$, Rutuja Shinde ${ }^{2}$, Vaibhavi Tornekar ${ }^{3}$, Dnyaneshwari Zagade ${ }^{4}$, Mrs. V.S.Sonar ${ }^{5}$ \\ Student, Department of Computer Engineering All India Shri Shivaji Memorial Society Polytechnic Kennedy road, Pune, \\ Maharashtra, India ${ }^{1-4}$ \\ Lecturer, Department of Computer Engineering All India Shri Shivaji Memorial Society Polytechnic Kennedy Road, Pune, \\ Maharashtra, India ${ }^{5}$
}

\begin{abstract}
The world is at the dawn of a smart phone era where everything in our day to day life is, and can be controlled via a smart phone. This smart phone usage is rapidly Evolving and has moved on from being just a device for voice calls and texting into a daily driver, which is being used to automate and control various day to day objects near and around us, some of which include lights, televisions, sound systems, air conditioners etc So in such a time where people are migrating to a smart phone based life, exercising control over things near and around them ,our project is aimed at developing a toy car to entertain kids and which can be controlled through a smart phone app. Making best use of the high end byte crushing processors in their hands, the app facilitates the user to control the toy car which attracts the child, plays with the child and also packs some additional features for entertainment of the user.
\end{abstract}

Keywords: User friendly, controlling automated car using Bluetooth of smartphone, it uses latest technologies and in built features of the smartphones.

\section{INTRODUCTION}

The world is at the dawn of a smart phone era where everything in our day to day life is, and can be controlled via a smart phone.

- The main purpose of this project is to develop a remote user interface to control a Robot via a wireless technology. There is a need to communicate with the robot remotely in order to control the robot movements and pass critical data both ways.

- In this project our aim is to use that Bluetooth for controlling a four wheeler car. We are much successful in achieving our goal.

- Our car runs well and it can be controlled by three modes.

- One, from any Bluetooth activated computers.

- Second, from an android phone by touching buttons and

- Third by the android's default accelerometer.

- Bluetooth controlled car is a robot which is built using Atmega8 Microcontroller in which serial communication is done via Bluetooth and
- Android Application and programming is done in embedded $\mathrm{C}$ language.

\section{IMPLEMENTATION}

A smart phone Android operated car. Now here is a simple to control your robot/robo car using Bluetooth module HC-06 with your android Smartphone device. The controlling devices of the whole system are an Arduino, Bluetooth module, DC motors are interfaced. The data receive by the Bluetooth module from android smart phone is fed as input to the controller. The controller acts accordingly on the DC motor of the robot car. The robot car in the project can be made to move in all the four directions using the android phone. The direction of the robot is indicators using LED indicators of the car system.

Initial step of this is to pair HC-05 Bluetooth module with mobile. Once the connection is established we need to press connect so that it gets triggered with a default password. There will be a predefined lookup table coded in a program which contents the information of direction and ASCII code.

Proposed Algorithm

- Step 1: Establish Communication between Android and Bluetooth Module.

- Step 2: Press Command input button from App.

- Step 3: Corresponding Command input string is send to Bluetooth Module. 
- Step 4: Check Command is received by the modules of Admin, Manage Application, Test Bluetooth module.

Management, Process Management, Manage Comment,

- Step 5: If "Disconnect" Command given then end communication.

- Step 6: Close Application.

\section{Algorithm for Arduino}

- Step 1: If input is received, check for a string received.

- $\quad$ Step 2: Compare contain of string received with pre-defined command in Arduino

- Step 3: Command matches with desired if-else block and motor will drive accordingly to output of that block.

- Step 4: If Command received is "Stop" entire process will stop.

- Step 5 If Command received is "Disconnect" it will reset all the codes.

\section{Design of the System}

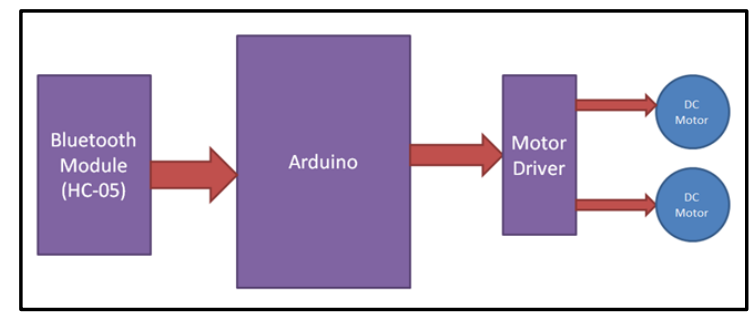

Here Smartphone is used as remote mobile which operates the car using Android Application and Bluetooth module to send instruction to microcontroller. Bluetooth module is used for wireless communication between two devices or no of devices. The instructions from Bluetooth module microcontroller play an important role and it sends its output to Motor driver so that motor can rotate and hence the car can be moved from one location to another.

\section{Advantages:}

$>$ Simple to operate.

$>$ Small parking area required.

$>$ Reduce human effort.

$>$ Control car from outside.

$>$ Reduce parking difficulties.

$>$ Easy to control car in off-road.

In future, we will also add more sensors so that car will be automatically controlled auto parking and auto turning. It will also increase the security for the both car and passengers in terrain condition.

\section{SYSTEM SPECIFICATION}

Planning before any activity is very much important. And if it is planned nicely, then success is guaranteed. Project Management System has six major
Reports. We analyzed the overall complexity of each of these modules and it was found that the project will required approximately 6 months completing, so we planned accordingly.

We decided to follow the SDLC i.e. Software Development Life Cycle while planning various phases of our project. This method consists of following activities:

1. Determination of system requirements

2. System Analysis

3. Design of system

4. Development of software

5. System Testing

6. Implementation and Evaluation

We have planned our project into following ways:

1. During first two month of our project, we have study the various problems.

2. During third month of our project, we have start to Analysis of problem.

3. During four and fifth month, we have start Designing and implementation of our project.

\section{CONCLUSION}

We achieved bluetooth control communication between the mobile -via android application- and the vehicle.

The knowledge is ever expanding and so are the problems which the mankind strive to solve. In this spirit, it is hoped that the current activity will lead to further enhancements.

\section{ACKNOWLEDGMENT}

We are doing this project and implementing this project under the guidance of Prof. V.S.Sonar, Professor AISSMS Polytechnic, Pune.

\section{REFERENCES}

[1]. Awab Fakih, JovitaSerrao, "Cell Phone Operated Robotic Car" International Journal of Scientific and Engineering Research, ISSN 2229-551.

[2]. Gupta, Sabuj Das, ArmanRiaz Ochi, Mohammad SakibHossain and NahidAlamSiddiqi"Designing \& Implementation of Mobile Operated Toy Car by DTMF" International Journal of Scientific \& Research Publications, Vol-3, Issue-1, 2013 ISSN 2250-3153.

[3]. Jadhav, Ashish, Mahesh Kumbhar and MeenakshiPawar"Cell Phone Controlled Ground Combat Vehicle" International Journal of Computer and Communication Engineering, Vol.1, No.2, July2012.

[4]. HebahH.O.Nasereddin\&Amjad Abdullah Abdelkarim, "SMARTPHONE CONTROL ROBOTS THROUGH BLUETOOTH" Middle East University, Amman, Jordan. Amman Arab University, Jordan. [5]. RitikaPahuja\&Narender Kumar, 


\section{IJARCCE}

"Android Mobile Phone Controlled Bluetooth Robot Using 8051 Microcontroller", International Journal of Scientific Engineering and Research (IJSER), Volume 2 issue 7, July 2014.

[6]. Banerji,Sourangsu. "Design and Implementation of an Unmanned Vehicle using a GSM network with Microcontrollers" International Journal of Science, Engineering and Technology Research 2.2(2013): pp-367-374.

[7]. Shashanka, D. "Password Protection for DTMF Controlled Systems without Using a Microcontroller", International Conference on Computing \& Control Engineering, 2012.

[8]. Edwin Wise, Robotics Demystified (Mc-GrawHill, 2005).

Websites

- $\quad$ www.instructables.com

- $\quad$ www.jeeexplore.ieee.org

- www.electronichub.org

- www.iaarc.org

- Google.com

- Robohub.com

- Electicalengineeringschools.org 